\title{
LEY ORGÁNICA DE COMUNICACIÓN COMENTADA, RESEÑA
}

por Juan Carlos Riofrío Martínez-Villalba, Corporación de Estudios y

Publicaciones (CEP), Quito, 2020, 411 págs.

COMMUNICATION ORGANIC LAW COMMENTED, REVIEW

by Juan Carlos Riofrío Martínez-Villalba, Corporación de Estudios y Publicaciones (CEP), Quito, 2020, 411 págs.

\section{Gabriela Rodríguez Llamas*}

Resumen: Este trabajo contiene tanto una reseña de la obra Ley Orgánica de Comunicación comentada del doctor Juan Carlos Riofrío MartínezVillalba, como un breve comentario a las profundas reformas hechas a esta ley en febrero de 2019. Se muestran aquí algunas luces y sombras de la reforma, siguiendo los comentarios del autor. Además se explica aquí cómo esta obra se inscribe en la colección Digesto ecuatoriano que la Corporación de Estudios y Publicaciones (CEP), junto a la Universidad de Los Hemisferios, está sacando adelante. En la primera parte hablamos sobre el autor y sobre la oportunidad de la obra. A continuación, en la parte II hablamos del objetivo de la reforma. Finalmente, en la parte III incluimos algunas conclusiones que nos ayudan a valorar la reforma y la obra comentada. Aunque sea muy positivo lo que se ha andado para reconquistar la libertad de expresión, siguiendo al autor, se echa de meno ahí la desaparición de los principios de la comunicación, que han quedado solo como estándares doctrinales en nuestro medio.

Palabras clave: Derecho de la información, derecho de la comunicación, derecho de la publicidad, censura previa, libertad de expresión

\footnotetext{
* Profesora titular de Derecho de la familia. Decana de la Facultad de Derecho de la Universidad de Los Hemisferios (Quito, Ecuador). https://orcid.org/0000-0002-9899-9574 gabrielar@uhemisferios.edu.ec
} 
Abstract: This work contains a review of the work "Organic Communication Law commented" by Dr. Juan Carlos Riofrío Martínez-Villalba, as well as a brief comment on the profound reforms made to this law made in February 2019. Some lights and shadows of this reform are shown here, following the author's commentaries. It is also explained here how this work is part of the Ecuadorian Digest collection, that the Corporación de Estudios $y$ Publicaciones (CEP), with the University of the Hemispheres, are taking forward. In the first part we talk about the author and about the opportunity of the work. Then, in Part II we discuss the aims of the reform. Finally, in Part III we include some conclusions that help us assess the reform and the commented work. Although what has been done to reconquer freedom of expression is very positive, following the author comments, we miss the disappearance of the principles of communication, which today only remain as doctrinal standards in our environment.

Keywords: Freedom of information, Communication Law, Advertising Law, Prior Restraint, Freedom of Expression

Sumario. I. Sobre el autor y sobre la oportunidad de la obra. II. El objetivo de la reforma. III. Algunas conclusiones.

\section{SOBRE EL AUTOR Y SOBRE LA OPORTUNIDAD DE LA OBRA}

El autor, que desde el año 2011 ha sido profesor de derecho de la información en la Universidad de Los Hemisferios, nos entrega ahora un nuevo libro en la materia de su especialización. Sobre esta rama del derecho ya antes había publicado varios libros, como Ley orgánica de transparencia y acceso a la información pública, comentada (CEP, Quito, 2005), El derecho de los secretos. Propuesta de una teoría general (Temis, Bogotá, 2008), La defensa de los signos distintivos de las religiones (Edusc, Roma, 2015), Régimen de la Comunicación (CEP, Quito, 2014) que sacó con otros autores, así como un centenar de artículos en diversas materias.

El Régimen de la Comunicación pertenece a la colección Digesto ecuatoriano, que la Corporación de Estudios y Publicaciones (CEP) saca adelante en conjunto con la Universidad de Los Hemisferios. En esta colección se agrupan leyes de manera temática, para luego ser comentadas por expertos del ramo. La obra que mencionamos fue escrita con la colaboración de los profesores Marcelo Marín Sevilla, Luis Fernando Bodero, Pablo Vásquez Buitrón. El Dr. Riofrío se encargó de la edición del 
libro, y comentó íntegramente la Ley Orgánica de Comunicación y parcialmente otras normas.

Después de las profundas reformas realizadas a esta Ley en febrero del año 2019 se vio necesario actualizar el comentario del año 2014. Entonces se pensó en hacer una nueva edición de todo el Régimen, pero como varias de las concordancias y de la normativa inferior que entonces fueron comentadas aún no se han actualizado en nuestra legislación, el autor prefirió solo sacar un comentario individualizado a la Ley Orgánica de Comunicación, donde se adjunta su Reglamento General, que es el que finalmente se ha publicado y que aquí comentamos.

El comentario hecho a la ley recoge tanto la posición de la Asamblea Nacional en cada artículo, como las objeciones que el Ejecutivo presentó a la reforma de ley, lo que servirá de mucho para en la labor hermenéutica determinar cuál fue la voluntad del legislador en cada artículo reformado. Los artículos se presentan con concordancias y jurisprudencia. Además, como ya es costumbre en la colección Digesto ecuatoriano, junto al texto vigente se presenta las normas derogadas (de manera tachada), a fin de facilitar la comparación de ambos textos y poder así determinar los puntos de continuidad y de discontinuidad en el tiempo.

Para realizar este comentario también el autor se sirve de las resoluciones que la antigua Superintendencia de la Información y Comunicación (hoy ya desaparecida), que en vida dictó y muestran algunas directrices sobre cómo deben interpretarse las disposiciones de la ley. Aunque no siempre sigue su criterio, al menos las toma en cuenta.

\section{EL OBJETIVO DE LA REFORMA}

El 20 de febrero de 2019 se promulgó la Ley 0 (R.O. Supl. 432), que reformó más del $75 \%$ de las disposiciones de la Ley Orgánica de Comunicación. ¿Cuál ha sido el principal móvil de la reforma? Sin duda en ella se han puesto en juego muchos intereses. El autor hace muchos comentarios sobre esto en su obra. En todo caso, resulta claro que el Preámbulo de la ley reformatoria pone todos los acentos en la libertad de expresión, invocando tratados a favor de esta libertad e incluso la Declaración de Chapultepec — que, de hecho, fue suscrita por el por Presidente de la República el mismo día en que las reformas se publicaron en el Registro Oficial. Ciertamente, el antiguo Preámbulo de la Ley ya mencionaba la libertad de expresión en los incisos 2 y 3 , pero la reforma lo destaca mucho más (vale tener esto en cuenta a la hora de leer el resto del 
articulado, porque este será el aire inspirador — la voluntad del legisladorde la más profunda reforma hecha a la ley).

Esto se halla en concordancia con la desaparición de la Supercom, entidad que controlaba la información de los medios y los sancionaba administrativamente con frecuencia. También ha desaparecido la antipática figura del Defensor de las Audiencias (antes prevista en el art. 73, hoy derogado), que en estricto rigor era un funcionario público que trabajaba dentro del medio de comunicación para denunciarlo. Prácticamente han desaparecido en esta ley las sanciones administrativas, así como el linchamiento mediático y otras exigencias que muchos consideraron desmedidas. ${ }^{1}$ Hoy hemos vuelto al esquema donde los actos comunicativos solo generan responsabilidad civil y penal.

En general, la propuesta de la Asamblea Nacional tuvo buena acogida del Presidente de la República, aunque el veto presidencial hizo muchas sugerencias. El Legislativo se allanó a 22 de las 26 objeciones presentadas por el Ejecutivo, y solo se ratificó en cuatro: (i) en el art. 86 sobre la acción afirmativa que hoy contiene muchos beneficios (un fondo permanente, puntos para concursos, tarifas preferenciales, crédito preferente, exenciones de impuestos, etc.); (ii) en el art. 91 sobre los archivos de soporte (cuyo texto queda casi igual al anterior); (iii) en el art. 94 que regula la publicidad de la misma manera que antes, aunque sin las sanciones administrativas (el veto que no prosperó pretendía derogar los incisos 3 y 4); y, (iv) en el art. 98, que sigue dando el monopolio de la publicidad nacional a los ecuatorianos (el veto pretendía volver a conceder el derecho de libertad de expresión a los extranjeros en este campo). Riofrío analiza en profundidad todas estas reformas, mostrando cuáles fueron los términos del debate.

\section{Algunas CONCLUSIONES}

La mayor reforma que ha tenido la LOC hasta el día de hoy se hizo con el ánimo de reconquistar la libertad de expresión, que se sentía perdida con las sanciones administrativas y la Supercom, hoy derogadas. Según Riofrío, la reforma ha traído muchas cosas buenas, pero tuvo sus límites y en alguna ocasión arrasó con ciertas disposiciones que tenían su peso y valía. En concreto, los principios de la comunicación que comenzaron a formularse

\footnotetext{
${ }^{1}$ En este sentido, se han derogado los arts. 26 del linchamiento mediático, 27 de la equidad en la publicidad de los casos judiciales, 29 de las restricciones a la libertad de información, entre otros, los cuales contenían penas administrativas severas. Hasta ha sido derogado el art. 59 que previa un tiempo para la caducidad y prescripción de las acciones administrativas, y el art. 64 que regulaba las medidas administrativas.
} 
en el año 2014, hoy han desaparecido. Desaparecieron del texto, no porque hoy se desea una comunicación contraria a esos principios (ni la reforma, ni nadie quiere discriminación en las comunicaciones, violentar derechos, falta de veracidad, etc.), sino porque resultaba absurda la obligación impuesta a los medios de comunicación de expedir cada uno un código deontológico impuesto por el Estado. En todo caso, según el autor, los principios de la comunicación han de seguir poniendo los estándares de la comunicación, al menos doctrinalmente.

En cuanto a la responsabilidad ulterior y la prohibición de la censura previa - así como en otros temas_-, Riofrío muestra que básicamente se han mantenido los estándares internacionales sobre la materia. Lo único que ha desaparecido son las responsabilidades adicionales que la LOC había creado (v.gr. la responsabilidad solidaria). Pese a la abundancia de artículos reformados, en la mayoría de los casos la reforma ha sido muy parcial, muy de forma.

Finalmente, en el debate político la reforma encontró algunas limitantes. Entre los artículos más debatidos, por ejemplo, encontramos que no se pudo volver a permitir que los extranjeros produzcan publicidad para el Ecuador (lo que es una seria restricción de su libertad de expresión). Todavía queda mucho trecho por andar. 